\title{
The Role of Platelet Function Analyzer Testing in Cardiac Surgery Transfusion Management
}

\section{Dejana Bogdanic ${ }^{a}$ Nenad Karanovic ${ }^{b}$ Jela Mratinovic-Mikulandra ${ }^{a}$ Branka Paukovic-Sekulic ${ }^{c}$ Dijana Brnic $^{d}$ Ivanka Marinovic ${ }^{e}$ Diana Nonkovic ${ }^{f}$ Nikolina Bogdanic $^{g}$}

\author{
a Department of Transfusion Medicine, University Hospital Center Split, Split, Croatia; \\ ${ }^{b}$ Department of Anesthesiology and Intensive Care, University Hospital Center Split, Split, Croatia; \\ c Department of Hematology Laboratory, University Hospital Center Split, Split, Croatia; \\ d Department of Diagnostic and Interventional Radiology, University Hospital Center Split, Split, Croatia; \\ e Department of Physical Medicine, University Hospital Center Split, Split, Croatia; \\ ${ }^{f}$ Department of Epidemiology, Teaching Institute of Public Health, Split, Croatia; \\ g University of Zagreb, School of Medicine, Zagreb, Croatia
}

\section{Keywords}

PFA-100 - Cardiac surgery · Transfusion management

\section{Summary}

Background: Identifying high-risk patients for transfusion after cardiac operations would alter postoperative management. The aim of this study was to investigate closure time (CT) measured by platelet function analyzer (PFA) for prediction of bleeding and transfusions. Methods: 66 patients were scheduled for coronary artery bypass graft (CABG) surgery and 30 patients for valve repair and replacement (non-CABG). Measurements of PFA- $100^{\circledR}$ CT for collagen and adenosine diphosphate (cADP) and collagen and epinephrine (cEPI) were performed $15 \mathrm{~min}$ after protamine administration. Blood loss was measured, and the amount of transfusion products was recorded postoperatively. Results: The study demonstrated significant differences between CABG patients with CADP-CT $\geq 118 \mathrm{~s}$ and those with CADP-CT < $118 \mathrm{~s}$ with regard to blood loss for $24 \mathrm{~h}(\mathrm{p}=0.001)$ and blood loss for $25-48 \mathrm{~h}$ ( $\mathrm{p}=0.003$ ) as well as fresh frozen plasma ( $p=0.015)$, platelet $(p>0.001)$ and red blood cell $(p=0.002)$ units given in 48 postoperative $h$. There were no differences cardiopulmonary bypass when was applied. In non-CABG patients, there were no differences in blood loss and transfusion requirements with respect to cADP-CT and cEPI-CT. Conclusion: Postoperative platelet dysfunction measured by a prolonged CADP-CT was significant predictor of blood loss and transfusion in CABG patients.

(C) 2017 S. Karger GmbH, Freiburg

\section{Introduction}

Patients undergoing cardiac surgery are at risk for excessive bleeding and associated complications [1]. Normal platelet function is essential for proper coagulation and hemostasis [2]. Bleeding often leads to transfusion of allogeneic blood and hemostatic blood components [3]. It is therefore important to assess the real versus the perceived need for transfusion of allogeneic RBCs and other blood products and to establish optimal management of bleeding and transfusion in patients undergoing cardiac surgery [4].Various tests can be used to monitor the functional abilities of platelets. The PFA- $100^{\circledR}$ is simple to use and gives quantitative results based on the principle of high shear stress simulating the environment at the site of vascular tissue injury, possibly making it more relevant than other tests in assessing shear-related platelet dysfunction [5]. Previous studies have shown that the PFA-100 test for assessing the risk of bleeding is subjected to uncertainties, doubts, and controversy. Four studies demonstrated a positive relationship between platelet function tests and postoperative bleeding [6-9]. On the contrary, Forestier et al. [10] and Fattorutto et al. [11] concluded that PFA-100 is not feasible for routine use following cardiac surgery, except for patients with increased risk of post-cardiopulmonary bypass (CPB) bleeding. Only one study has investigated platelet function test for prediction of bleeding and transfusion requirements in non-CPB surgery [12]. Two studies concluded that PFA-100, especially the test sequence with the collagen and adenosine diphosphate (cADP) cartridge, was very useful for platelet function monitoring $[13,14]$.

The aim of our study was to investigate the association between platelet function as determined by PFA-100 testing and postoperative blood loss and need for transfusion of blood products in i) patients undergoing coronary artery bypass grafting (CABG) and ii) patients with cardiac valve repair and replacement (non-CABG).

\section{KARGER}

() 2017 S. Karger GmbH, Freiburg 


\section{Patients and Methods}

\section{Study Design}

After Medical Ethics Committee of University Hospital Center Split approval (protocol number: 2181-147-01 approved at February 20, 2012) and written consent, 126 patients undergoing cardiac surgery were included between May 2014 and May 2015. After 30 of them were excluded at the different stages of research, 96 patients undergoing cardiac surgery (69 males and $27 \mathrm{fe}-$ males aged between 43 and 84 years) were investigated (fig. 1). According to the prospective study design, the patients were divided into two main groups based on type of surgical intervention. Within each group, patients were divided in two subgroups i) with cADP closure time (CT) $\geq 118 \mathrm{~s}$ versus cADP-CT $<118 \mathrm{~s}$ or ii) with collagen and epinephrine closure time (cEPI-CT) $\geq 165 \mathrm{~s}$ versus cEPI-CT $<165$ s. Criteria for non-inclusion in the study: emergency operation, renal insufficiency (creatinine $>120 \mu \mathrm{mol} / \mathrm{l}$, glomerular filtration rate (GRF) $<60 \mathrm{ml} / \mathrm{min}$ ), hepatic impairment (bilirubin $>50 \mu \mathrm{mol} / \mathrm{l}$ ), medical history of bleeding tendencies, disorders of coagulation status in standard coagulation tests: platelet (PLT) count $<100 \times 10^{9} / \mathrm{l}$, prothrombin time (PT) $<0.70 \mathrm{~s}$, activated partial thromboplastin time (APTT) $>33 \mathrm{~s}$, hemoglobin $(\mathrm{Hb})<10 \mathrm{~g} / \mathrm{dl}$, hematocrit $(\mathrm{Hct})<0.28$, fibrinogen $<1.8 \mathrm{~g} / \mathrm{l}$, before surgery and usage of antiPLT agents within 5 days before operation. CTs by PFA- 100 longer than the reference ranges may be caused by a Hct less than $28 \%$ or PLT count less than $100 \times 10^{9} / \mathrm{l}$. On the recommendation of Clinical Hematology Laboratory that complies with the manufacturer's recommendations patients with $\mathrm{Hct}<28 \%$ or PLT count $<100 \times 10^{9} / 1$ measured 15 min following administration of protamine were excluded from the study .

All patients underwent standardized anesthesia and surgical protocol. CPB was performed under moderate hypothermia $\left(34^{\circ} \mathrm{C}\right)$ and with usage of heparin-coated circuits. Heparin was administered as a loading dose of $150 \mathrm{IU} / \mathrm{kg}$ of body weight and supplemented to maintain an activated clotting time (ACT) of more than $280 \mathrm{~s}$ during $\mathrm{CPB}$. After CPB, heparin was neutralized with protamine sulfate (1,5 mg of protamine/100 IU of heparin) to an ACT of less than $130 \mathrm{~s}$. In patients without use of $\mathrm{CPB}$, heparin was administered as a loading dose of $150 \mathrm{IU} / \mathrm{kg}$ of body weight to reach ACT $\geq 280 \mathrm{~s}$ and was neutralized with protamine sulfate at the same dosage as in patients with CPB. Red blood cells (RBCs), PLTs and fresh frozen plasma (FFP) were administered in accordance with recent recommendations and guidelines according to the decision of the cardiac anesthesiologists in charge [15]. RBCs were transfused to maintain $\mathrm{Hb}$ concentrations between 9 and $11 \mathrm{~g} / \mathrm{dl}$, considering the dynamics of bleeding $[15,16]$. FFP was given to maintain hemostasis when the international normalized ratio exceeded 1.5 [17]. In the postoperative period, PLTs were administered as indicated in patients with microvascular bleeding and in those with PLT counts below $100 \times 10^{9} / 1[17]$.

Blood samples were collected and analyzed at one time point, $15 \mathrm{~min}$ after administration of protamine. Additionally, the following demographic and sur- gical data were collected: sex, body weight (kg), age (years), chest tube drainage $(\mathrm{ml})$ at 24 and $48 \mathrm{~h}$ after admission in the intensive care unit (ICU) - a measure of postoperative blood loss, use of blood products(FFP, PLTs and RBCs) given during the operative or postoperative 48 -hour period. $\mathrm{Hct}, \mathrm{Hb}$ and PLT counts were measured in a hematology analyzer (Advia 120; Bayer, Tarrytown, NY, USA). PT, aPTT, and fibrinogen were analyzed with a coagulation analyzer Behring Coagulation System (Siemens Diagnostic Inc., Marburg, Germany) using manufacturer's kits and recommendations.

Platelet function was tested using the PFA-100 (Siemens AG, Erlangen, Germany); citrated whole blood was aspirated at high shear rates through disposable cartridges containing an aperture within a membrane coated either with cADP or cEPI [18]. These agonists induced platelet adhesion, activation, and aggregation leading to rapid occlusion of the aperture and cessation of blood flow. The time needed for blood flow cessation is termed CT and measured in seconds. An abnormally prolonged CT was considered to be $\geq 165 \mathrm{~s}$ for a cEPI cartridge, and $\geq 118 \mathrm{~s}$ for a cADP cartridge. As recommended by the manufacturer, blood samples were collected into 3,2\% sodium citrate tubes of 4,5 ml (Vacutainer; Becton-Dickinson, Franklin Lakes, NJ, USA).

\section{Statistical Analysis}

Data were defined as continuous and categorical variables. Categorical variables are expressed as percentages and continuous variables as mean \pm standard deviation (SD). Patients were divided in two subgroups i) with cADP-CT $\geq 118$ $\mathrm{s}$ versus cADP-CT $<118 \mathrm{~s}$, or ii) with cEPI-CT $\geq 165 \mathrm{~s}$ versus cEPI-CT $<165 \mathrm{~s}$. Comparison between subgroups was made by using the Student's t-test to test the differences between the two arithmetic means in the subgroups. According to power analysis, an estimated number of 33 patients in each subgroup was needed at a statistical power of $90 \%$ and significance level of $5 \%$ to detect clinically meaningful differences of blood loss and transfusion requirements in the CABG group. For sample size analysis, PASS 11 (NCSS Inc., Kaysville, UT, USA) was used. A p value $\leq 0.05$ was considered statistically and clinically significant with respect to the effect size and performed power analysis. All statistical analyses were performed using computer software (SPSS 17.0; SPSS, Inc., Chicago, IL, USA).

\section{Results}

Out of 126 patients, 30 patients were excluded because of i) insufficient blood sample for PFA-100 testing $(\mathrm{n}=10)$, iii) Hct < $0.28(\mathrm{n}=6)$, iii) PLT count $<100 \times 10^{9} / 1(\mathrm{n}=4)$, and iv) revision for postoperative bleeding $(\mathrm{n}=10)$ (fig. 1$)$.

Fig. 1. Flow diagram.

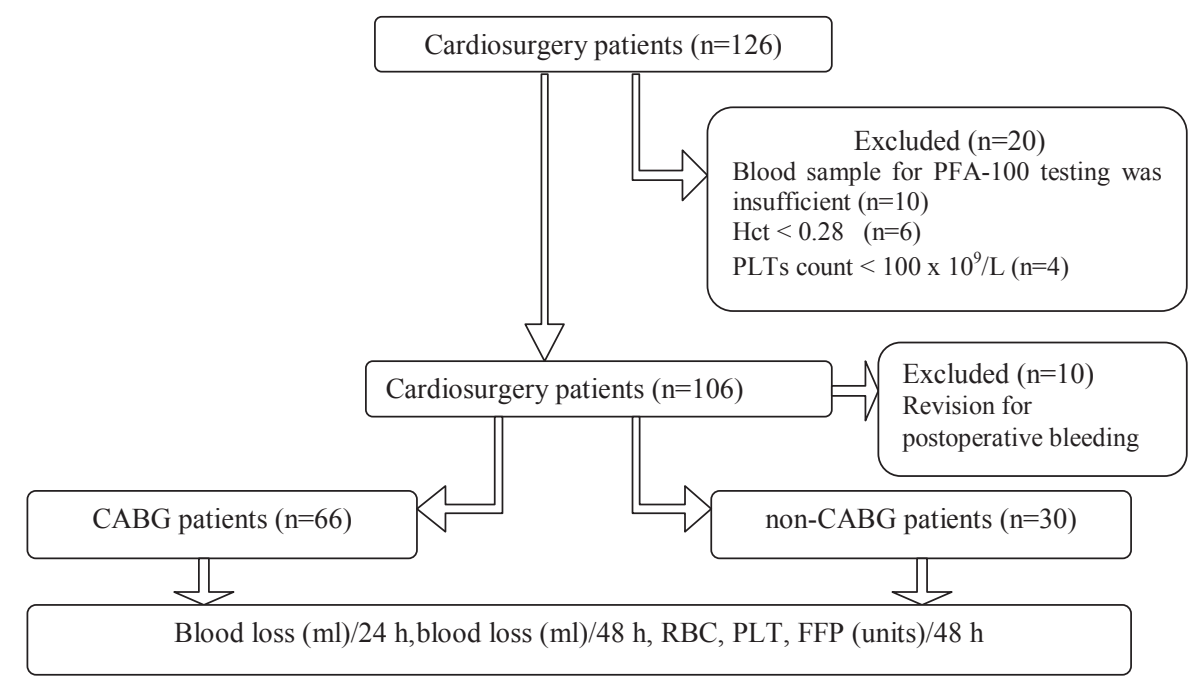


Table 1. Patient-related preoperative, perioperative and postoperative variables

Table 2. The difference between groups with cADP-CT $\geq 118 \mathrm{~s}$ and cADP-CT $<118 \mathrm{~s}$ in CABG patients

\begin{tabular}{lll}
\hline & $\begin{array}{l}\text { CABG } \\
(\mathrm{n}=66)\end{array}$ & $\begin{array}{l}\text { non-CABG } \\
(\mathrm{n}=30)\end{array}$ \\
\hline Age, years & $67 \pm 11$ & $69 \pm 8$ \\
Male sex (\%) & $55(83 \%)$ & $14(47 \%)$ \\
Body mass index, $\mathrm{kg} / \mathrm{m}^{2}$ & $29 \pm 4$ & $26 \pm 4$ \\
Hypertension (\%) & $49(74 \%)$ & $12(40 \%)$ \\
Hyperlipidemia (\%) & $41(62 \%)$ & $10(33 \%)$ \\
Diabetes mellitus (\%) & $12(18 \%)$ & $6(20 \%)$ \\
Smokers (\%) & $25(38 \%)$ & $11(27 \%)$ \\
Creatinine, $\mu$ mol/1 & $84 \pm 18.5$ & $89.6 \pm 23.6$ \\
GRF, ml/min & $82.9 \pm 13.2$ & $85.6 \pm 14.1$ \\
Bilirubin, $\mu$ mol/l & $30.4 \pm 22.2$ & $31.5 \pm 18.3$ \\
Previous myocardial infarction (\%) & $10(15 \%)$ & 0 \\
Withdrawal of clopidogrel at least 5 days before surgery (\%) & $33(50 \%)$ & $5(17 \%)$ \\
Without of clopidogrel therapy in medical history (\%) & $33(50 \%)$ & $25(83 \%)$ \\
Withdrawal of ASA at least 5 days before surgery (\%) & $42(74 \%)$ & $20(67 \%)$ \\
Without of ASA therapy in medical history (\%) & $24(26 \%)$ & $10(33 \%)$ \\
CPB & $22(33 \%)$ & $30(100 \%)$ \\
PLT number $\times 10 \% / 1$ & $197 \pm 59$ & $160 \pm 43$ \\
Hct & $0.35 \pm 0.04$ & $0.31 \pm 0.02$ \\
Hb, g/l & $120 \pm 15$ & $114 \pm 13$ \\
Fibrinogen, g/l & $3.3 \pm 0.9$ & $2.7 \pm 0.8$ \\
cEPI-CT, s & $180 \pm 77$ & $232 \pm 62$ \\
cADP-CT, s & $141 \pm 83$ & $195 \pm 77$ \\
24-hour drain volume, ml & $664 \pm 446$ & $282 \pm 155$ \\
25- to 48-hour drain volume, ml & $338 \pm 237$ & $229 \pm 166$ \\
$\geq 2$ units of RBCs / 48 h (\%) & $28(42 \%)$ & $9(30 \%)$ \\
$\geq 1$ units of FFP / $48 \mathrm{~h}(\%)$ & $15(23 \%)$ & $6(20 \%)$ \\
$\geq 4$ units of PLTs / 48 h (\%) & $23(35 \%)$ & $2(7 \%)$ \\
\hline
\end{tabular}

\begin{tabular}{|c|c|c|c|}
\hline & $\begin{array}{l}\text { cADP-CT } \geq 118 \mathrm{~s} \\
(\mathrm{n}=32)\end{array}$ & $\begin{array}{l}\text { cADP-CT }<118 \mathrm{~s} \\
(\mathrm{n}=34)\end{array}$ & $\mathrm{p}$ \\
\hline Age, years & $66 \pm 10$ & $67 \pm 5$ & 0.063 \\
\hline Body mass index, $\mathrm{kg} / \mathrm{m}^{2}$ & $27 \pm 2$ & $29 \pm 3$ & 0.062 \\
\hline Hypertension (\%) & $29(90 \%)$ & $20(59 \%)$ & 0.003 \\
\hline Hyperlipidemia (\%) & $18(56 \%)$ & $23(68 \%)$ & 0.062 \\
\hline Diabetes mellitus (\%) & $5(16 \%)$ & $7(20 \%)$ & 0.065 \\
\hline Smokers (\%) & $16(50 \%)$ & $9(26 \%)$ & 0.004 \\
\hline Creatinine, $\mu \mathrm{mol} / \mathrm{l}$ & $83 \pm 16.5$ & $84 \pm 10.5$ & 0.623 \\
\hline $\mathrm{GRF}(\mathrm{ml} / \mathrm{min})$ & $80.7 \pm 11.2$ & $82.8 \pm 10.2$ & 0.675 \\
\hline Bilirubin, $\mu \mathrm{mol} / \mathrm{l}$ & $30.1 \pm 16.2$ & $33.2 \pm 15.2$ & 0.545 \\
\hline $\mathrm{CPB}$ & 12 & 10 & 0.064 \\
\hline Time of $\mathrm{CPB}, \mathrm{min}$ & $160 \pm 50$ & $154 \pm 35$ & 0.567 \\
\hline PLT number $\times 10^{9} / 1$ & $190 \pm 54$ & $202 \pm 62$ & 0.444 \\
\hline $\mathrm{Hb}, \mathrm{g} / \mathrm{l}$ & $116 \pm 14$ & $124 \pm 15$ & 0.535 \\
\hline Hct & $0.34 \pm 0.04$ & $0.36 \pm 0.04$ & 0.020 \\
\hline Fibrinogen, $g / 1$ & $3.0 \pm 0.9$ & $3.5 \pm 1.0$ & 0.051 \\
\hline cEPI-CT, $s$ & $211 \pm 74$ & $152 \pm 69$ & 0.001 \\
\hline 24 -hour drain volume, $\mathrm{ml}$ & $847 \pm 493$ & $486 \pm 317$ & 0.001 \\
\hline 25 - to 48 -hour drain volume, $\mathrm{ml}$ & $423 \pm 271$ & $257 \pm 163$ & 0.003 \\
\hline \multicolumn{4}{|l|}{ Intraoperatively } \\
\hline RBCs, U & $3.2 \pm 1.8$ & $1.8 \pm 1.7$ & 0.002 \\
\hline FFP, U & $3.6 \pm 1.2$ & $2.8 \pm 0.7$ & 0.003 \\
\hline \multicolumn{4}{|l|}{ Postoperatively } \\
\hline RBCs, U & $2.5 \pm 2.2$ & $1.0 \pm 1.5$ & 0.002 \\
\hline FFP, U & $1.5 \pm 2.4$ & $0.4 \pm 1.3$ & 0.015 \\
\hline PLTs, U & $5.1 \pm 5.6$ & $0.8 \pm 2.6$ & $<0.001$ \\
\hline
\end{tabular}


Fig. 2. Correlation between values of $c A D P-C T$ and blood loss for $24 \mathrm{~h}$ in CABG group.
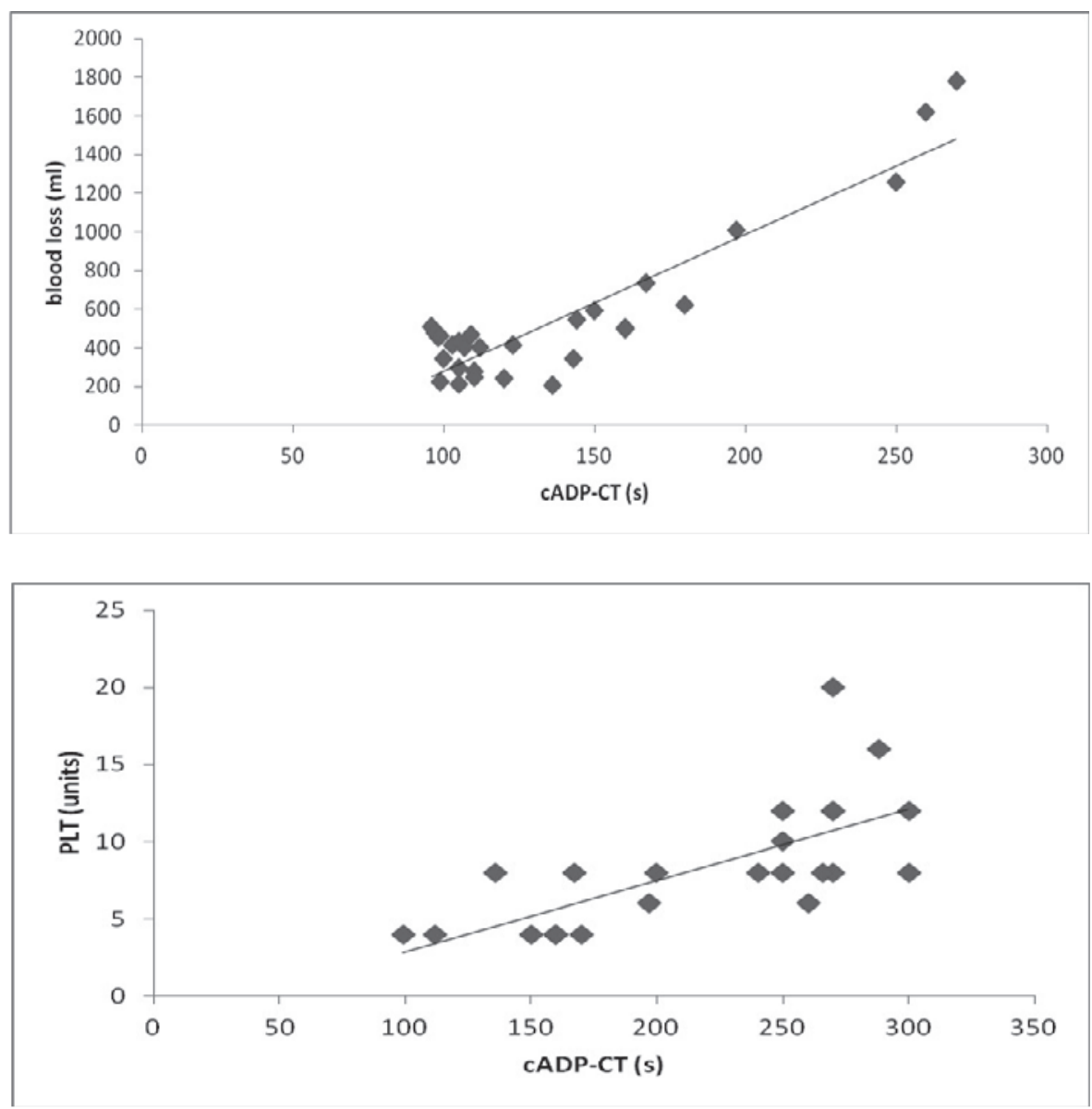

Fig. 3. Correlation between values of cADP-CT and PLT for $48 \mathrm{~h}$ in CABG group. cal history, Hct values, blood loss in $24 \mathrm{~h}$, blood loss in $25-48 \mathrm{~h}$ as well as FFP, PLT and RBC units given in the first 48 postoperative h (table 2). 14 (20\%) patients had a cADP-CT > 200 s. They consumed 140 (70\%) of total of 194 units of PLTs. The scatter diagrams showed strong correlations between CADP-CT and blood loss in $24 \mathrm{~h}$ (fig. 2) and between cADP-CT and PLT in $48 \mathrm{~h}$ (fig. 3). In the subgroups of CABG patients with cEPI-CT $\geq 165 \mathrm{~s}$ and $<$ $165 \mathrm{~s}$, there were significant differences of Hct values, but no differences with regard to blood loss in $24 \mathrm{~h}$ and in $25-48 \mathrm{~h}$ as well as FFP, PLT and RBC units given in the first 48 postoperative $h$ (table 3). In contrast, in the subgroups of non-CABG patients with cADP-CT $\geq 118 \mathrm{~s}$ and $<118 \mathrm{~s}$ (table 4 ) and in those with cEPI-CT $\geq 165 \mathrm{~s}$ and $<165 \mathrm{~s}$ (table 5), blood loss in $24 \mathrm{~h} 25-48 \mathrm{~h}$ as well as FFP, PLT and RBC units given during $48 \mathrm{~h}$ postoperatively did not differ.

\section{Discussion}

To our knowledge, this is the first study to investigate postoperative CADP-CT and CEPI-CT in relation with postoperative blood loss and transfusion requirements in two specific groups of patients (CABG and non-CABG). So there is no possibility to compare our study to any other. We took into consideration CADP-CT and CEPI-CT. CADP-CT is prolonged in all cases of impairment of 
Table 3. The difference between groups with cEPI-CT $\geq 165 \mathrm{~s}$ and cEPI-CT $<165 \mathrm{~s}$ in CABG patients

Table 4. The difference between groups with cADP-CT $\geq 118 \mathrm{~s}$ and CADP-CT $<118 \mathrm{~s}$ in non-CABG patients

\begin{tabular}{|c|c|c|c|}
\hline & $\begin{array}{l}\text { cEPI-CT } \geq 165 \mathrm{~s} \\
(\mathrm{n}=31)\end{array}$ & $\begin{array}{l}\text { cEPI-CT<165 s } \\
(\mathrm{n}=35)\end{array}$ & $\mathrm{p}$ \\
\hline Age, years & $66 \pm 8$ & $67 \pm 4$ & 0.367 \\
\hline Body mass index, $\mathrm{kg} / \mathrm{m}^{2}$ & $28 \pm 3$ & $29 \pm 2$ & 0.421 \\
\hline Hypertension (\%) & $22(71 \%)$ & $27(77 \%)$ & 0.067 \\
\hline Hyperlipidemia (\%) & $20(65 \%)$ & $21(60 \%)$ & 0.420 \\
\hline Diabetes mellitus (\%) & $7(23 \%)$ & $5(14 \%)$ & 0.410 \\
\hline Smokers (\%) & $13(42 \%)$ & $12(34 \%)$ & 0.375 \\
\hline Creatinine, $\mu \mathrm{mol} / \mathrm{l}$ & $82.8 \pm 16.5$ & $83 \pm 12.5$ & 0.645 \\
\hline $\mathrm{GRF}, \mathrm{ml} / \mathrm{min}$ & $82.7 \pm 10.2$ & $80.5 \pm 9.2$ & 0.667 \\
\hline Bilirubin, $\mu \mathrm{mol} / \mathrm{l}$ & $31.5 \pm 14.2$ & $32.2 \pm 14.5$ & 0.589 \\
\hline $\mathrm{CPB}$ & $15(48 \%)$ & $7(20 \%)$ & 0.020 \\
\hline Time of $\mathrm{CPB}$, min & $165 \pm 30$ & $140 \pm 15$ & 0.030 \\
\hline PLT number $\times 10^{9} / 1$ & $192 \pm 53$ & $201 \pm 64$ & 0.430 \\
\hline $\mathrm{Hb}, \mathrm{g} / \mathrm{l}$ & $115 \pm 14$ & $124 \pm 15$ & 0.470 \\
\hline Hct & $0.33 \pm 0.04$ & $0.37 \pm 0.04$ & 0.001 \\
\hline Fibrinogen, g/l & $2.9 \pm 0.7$ & $3.6 \pm 1.0$ & 0.007 \\
\hline cADP-CT, s & $176 \pm 78$ & $122 \pm 47$ & 0.001 \\
\hline 24-hour drain volume, $\mathrm{ml}$ & $693 \pm 462$ & $632 \pm 438$ & 0.582 \\
\hline 25- to 48 -hour drain volume, $\mathrm{ml}$ & $347 \pm 244$ & $329 \pm 231$ & 0.766 \\
\hline \multicolumn{4}{|l|}{ Intraoperatively } \\
\hline RBCs, U & $3.0 \pm 1.6$ & $1.9 \pm 2.0$ & 0.021 \\
\hline FFP, $\mathrm{U}$ & $3.4 \pm 1.4$ & $3.0 \pm 0.6$ & 0.183 \\
\hline \multicolumn{4}{|l|}{ Postoperatively } \\
\hline RBCs, U & $2.1 \pm 2.3$ & $1.3 \pm 1.6$ & 0.102 \\
\hline FFP, U & $1.1 \pm 2.3$ & $0.8 \pm 1.7$ & 0.186 \\
\hline PLTs, U & $3.7 \pm 5.7$ & $2.2 \pm 3.7$ & 0.153 \\
\hline
\end{tabular}

\begin{tabular}{llll}
\hline & $\begin{array}{l}\text { cADP-CT } \geq 118 \mathrm{~s} \\
(\mathrm{n}=23)\end{array}$ & $\begin{array}{l}\text { cADP-CT }<118 \mathrm{~s} \\
(\mathrm{n}=7)\end{array}$ & $\mathrm{p}$ \\
\hline Age, years & $70 \pm 5$ & $69 \pm 2$ & 0.425 \\
Body mass index, $\mathrm{kg} / \mathrm{m}^{2}$ & $25 \pm 7$ & $26 \pm 3$ & 0.402 \\
Hypertension (\%) & $9(40 \%)$ & $3(43 \%)$ & 0.456 \\
Hyperlipidemia (\%) & $8(35 \%)$ & $2(29 \%)$ & 0.064 \\
Diabetes mellitus (\%) & $4(17 \%)$ & $2(29 \%)$ & 0.058 \\
Smokers (\%) & $9(39 \%)$ & $2(29 \%)$ & 0.077 \\
Creatinine, $\mu$ mol/l & $89.3 \pm 19.6$ & $87.6 \pm 21.6$ & 0.467 \\
GRF, ml/min & $82.6 \pm 12.1$ & $84.8 \pm 13.5$ & 0.478 \\
Bilirubin, $\mu$ mol/l & $30.8 \pm 16.3$ & $31.4 \pm 17.3$ & 0.523 \\
Time of CPB, min & $170 \pm 30$ & $160 \pm 40$ & 0.065 \\
PLT number $\times 10^{9} / 1$ & $153 \pm 36$ & $182 \pm 59$ & 0.266 \\
Hb, g/l & $110 \pm 13$ & $98 \pm 11$ & 0.310 \\
Hct & $0.32 \pm 0.04$ & $0.30 \pm 0.03$ & 0.115 \\
Fibrinogen, g/l & $2.7 \pm 0.6$ & $2.7 \pm 1.3$ & 0.900 \\
cEPI-CT, s & $241 \pm 54$ & $201 \pm 80$ & 0.252 \\
24-hour drain volume, $\mathrm{ml}$ & $294 \pm 147$ & $238 \pm 185$ & 0.482 \\
25- to 48-hour drain volume, $\mathrm{ml}$ & $240 \pm 179$ & $190 \pm 114$ & 0.492 \\
Intraoperatively & & & \\
$\quad$ RBCs, U & $3.7 \pm 1.8$ & $2.9 \pm 2.2$ & 0.250 \\
$\quad$ FFP, U & $3.0 \pm 1.1$ & $3.6 \pm 0.8$ & 0.267 \\
Postoperatively & & & \\
$\quad$ RBCs, U & $0.9 \pm 1.2$ & $1.0 \pm 1.5$ & 0.817 \\
$\quad$ FFP, U & $0.4 \pm 1.0$ & $0.7 \pm 1.5$ & 0.508 \\
$\quad$ PLTs, U & $0.2 \pm 0.8$ & $0.6 \pm 1.5$ & 0.527 \\
\hline
\end{tabular}


Table 5. The difference between groups with cEPI-CT $\geq 165 \mathrm{~s}$ and cEPI-CT $<165 \mathrm{~s}$ in nonCABG patients

\begin{tabular}{llll}
\hline & $\begin{array}{l}\text { cEPI-CT } \geq 165 \mathrm{~s} \\
(\mathrm{n}=26)\end{array}$ & $\begin{array}{l}\text { cEPI-CT }<165 \mathrm{~s} \\
(\mathrm{n}=4)\end{array}$ & $\mathrm{p}$ \\
\hline Age, years & $68 \pm 8$ & $69 \pm 3$ & 0.587 \\
Body mass index, $\mathrm{kg} / \mathrm{m}^{2}$ & $25 \pm 6$ & $26 \pm 4$ & 0.562 \\
Hypertension (\%) & $10(38 \%)$ & $2(50 \%)$ & 0.056 \\
Hyperlipidemia (\%) & $9(35 \%)$ & $1(25 \%)$ & 0.058 \\
Diabetes mellitus (\%) & $6(23 \%)$ & $0(0 \%)$ & 0.002 \\
Smokers (\%) & $9(35 \%)$ & $2(50 \%)$ & 0.054 \\
Creatinine, $\mu$ mol/l & $87.3 \pm 17.6$ & $89.1 \pm 16.5$ & 0.592 \\
GRF, ml/min & $82.68 \pm 10.5$ & $84.5 \pm 14.3$ & 0.534 \\
Bilirubin, $\mu$ mol/l & $30.4 \pm 15.1$ & $31.2 \pm 18.3$ & 0.621 \\
Time of CPB, min & $180 \pm 30$ & $150 \pm 50$ & 0.003 \\
PLT number $\times 10^{9} / 1$ & $154 \pm 36$ & $202 \pm 67$ & 0.249 \\
Hb, g/l & $107 \pm 14$ & $105 \pm 7.0$ & 0.599 \\
Hct & $0.32 \pm 0.04$ & $0.30 \pm 0.02$ & 0.304 \\
Fibrinogen, g/l & $2.8 \pm 0.8$ & $2.4 \pm 0.4$ & 0.930 \\
cADP-CT, s & $201 \pm 72$ & $146 \pm 77$ & 0.252 \\
24-hour drain volume, ml & $296 \pm 160$ & $180 \pm 43$ & 0.166 \\
25- to 48-hour drain volume, $\mathrm{ml}$ & $223 \pm 169$ & $199 \pm 159$ & 0.707 \\
Intraoperatively & & & \\
$\quad$ RBCs, U & $3.9 \pm 1.6$ & $0.8 \pm 0.5$ & 0.001 \\
$\quad$ FFP, U & $2.9 \pm 0.9$ & $4.8 \pm 1.0$ & 0.001 \\
Postoperatively & & & \\
$\quad$ RBCs, U & $1.0 \pm 1.3$ & $0.5 \pm 1.0$ & 0.508 \\
FFP, U & $0.5 \pm 1.2$ & $0.0 \pm 0.0$ & 0.374 \\
$\quad$ PLTs, $\mathrm{U}$ & $0.3 \pm 1.0$ & $0.0 \pm 0.0$ & 0.581 \\
\hline
\end{tabular}

PLT activity associated with cardiac surgery, including the residual effect of clopidogrel [19] and external effects on PLTs by heparin as well as usage of CPB and colloid and crystalloid solutions [20,21]. The reason for the use of CT The time point for blood sample withdrawal $15 \mathrm{~min}$ after administration of protamine was the result of previous investigations showing that the CT after cardiac surgery was the best predictor of blood loss $[6,7]$. This measurement will give information regarding differences in baseline hemostatic capacity of the blood among the patients and information about the influence of all hemostatic disturbances related to cardiac surgery.

In our study group of CABG patients, significant differences were found with regard to blood loss $/ 24 \mathrm{~h}$ and blood loss/25-48 $\mathrm{h}$ between patients with cADP-CT $\geq 118 \mathrm{~s}$ and those with CADP-CT $<118$ s, confirming similar finding by Poston and colleagues [12]. We showed that the higher the values of CADP-CT in the CABG group the higher were the intra- and postoperative blood loss and transfusion requirements (fig. 2, 3).

In non-CABG patients we did not find any association either between CADP-CT and blood loss / transfusion requirements postoperatively or between cEPI-CT and blood loss / transfusion requirements. Our observations can be explained by the fact that primary hemostasis disturbance is a reversible process in non-CABG patients, and after elimination of external triggers hemostasis recovers spontaneously. Similarly Pappalardo and colleagues [21] showed that a defective primary hemostasis in these patients is not associated with an increased risk of bleeding. In our study, volume of bleeding and consumption of blood products were higher in the
$\mathrm{CABG}$ group than in the non-CABG group. In $\mathrm{CABG}$ patients, recovery of primary hemostasis, if there is a disturbance, cannot be achieved without blood product transfusions $[16,17]$.

We therefore conclude that CADP-CT testing following administration of protamine in the CABG group may identify patients in need for higher amounts of blood products. These patients would be the ones who could receive early initiation of cADP-CT testing and therefore derive the most benefit. In contrast, cEPI-CT was not predictive of bleeding and transfusion requirements either in the $\mathrm{CABG}$ and or in the non-CABG group. Cardiosurgery-related bleeding and transfusions requirements are strongly influenced by antiplatelet therapy before surgery [22]. The antiplatelet therapy before surgery was different in CABG and non-CABG patients. Clopidogrel therapy in $\mathrm{CABG}$ group is characterized by a large interindividual variability in pharmacodynamic response and in time to recover normal platelet reactivity following cessation of clopidogrel [23]. Theoretically, the PFA-100 cADP cartridge may be more suitable for monitoring clopidogrel therapy than the cEPI cartridge, but both collagen activation and ADP acting through the P2Y1 receptor, along with the high shear conditions, may be normally sufficient to largely overcome P2Y12 blockade. Some studies have shown that CADP is not suitable for assessing the efficacy of clopidogrel therapy [24-26]. The Innovance PFA P2Y was found to have a high sensitivity for the detection of platelet P2Y12-receptor blockade in patients undergoing therapy with a $\mathrm{P} 2 \mathrm{Y} 12$ receptor antagonist [26], but clopidogrel therapy is not the only reason for the impairment of platelet function in CABG patients. Effects of heparin, hypothermia and fibrinolytic activity may also contribute 
to the platelet function defect, as well as commonly used medications such as nonsteroidal anti-inflammatory drugs, some antibiotics, diuretics, and antihypertensives. Platelet plug formation in the PFA system is affected by a reduced level or function of von Willebrand factor (vWF). The severity of the cardiovascular disease indicated by higher vascular wall shear stress may produce changes of vWF structure. This was supported by the fact that approximately $90 \%$ patients with hypertension had prolonged PFA time (subgroup of cADP-CT value $\geq 118 \mathrm{~s}$ ). A normal concentration of vWF, therefore, is not sufficient to support platelet adhesion and aggregation if the molecular structure of vWF is not preserved. During aging, the arterial system narrows thus increasing shear stress; this may result in activation of platelets and also in adsorption and prolonged loss of large multimers of vWF unlike transitory and reversible loss and dysfunction of vWF caused by $\mathrm{CPB}$ [27]. We showed significant differences of cEPI-CT values depending on the use of CPB, but cEPI-CT was not predictive of bleeding and transfusions requirements.

On the other hand, patients with impairment of platelet function and with subsequently increased consumption of blood products can be identified by cADP-CT testing.

In our study, there were significant differences of Hct values in cADP-CT and cEPI-CT subgroups of the CABG group. These differences were only clinically significant for the CADP-CT subgroups as cEPI-CT subgroups did not differ with respect to blood loss and transfusions requirements.

Further, there were no significant differences of plasma fibrinogen levels in subgroups with cADP-CT $\geq 118$ s versus cADP-CT < $118 \mathrm{~s}$ in $\mathrm{CABG}$ and non-CABG group.

This study has some limitations. PFA-100 testing is very sensitive to vWF levels, and vWF measurement was not done. However, thorough and careful history of bleeding tendencies was performed for all the patients included in the study compensating for the missing vWF determination. The differences in blood loss between subgroups in the non-CABG group did not have any clinical or statistical significance because they did not result in increased consumption of blood products. Therefore, a sample of 30 non-CABG patients is sufficient for statistical analysis. Another possible limitation is that $\mathrm{CABG}$ patients were not divided according to the fact whether or not $\mathrm{CPB}$ was applied. However, we could demonstrate that there were no significant differences in CADP-CT values between CAPG patients with and without $\mathrm{CPB}$. This is in line with an article by Poston [28] who also did not find any of bleeding rates in patients with or without $\mathrm{CPB}$. Therefore, we abstained from dividing our CABG group into additional subgroups. Thus the main limitation of our study is that in many cases routine administration of transfusion products mainly depended on the discretion of individual anesthesiologist in charge.

In summary, our study demonstrates that cADP-CT at time point of 15 min following administration of protamine may predict blood loss as well as FFP, PLT and RBC transfusion requirements only in CABG patients. Identifying high-risk patients for transfusion would alter postoperative patient management. In our opinion prediction models based on a postoperative PFA-100 test may facilitate blood component management following cardiac surgery and, at the same time, decrease potential negative influence of excessive transfusion of blood products.

\section{Disclosure Statement}

The authors declare no conflict of interest.

\section{References}

1 Whitlock R, Crowther MA, Ng HJ: Bleeding in cardiac surgery: its prevention and treatment - an evidencebased rewiew. Crit Care Clin 2005;21:589-610.

2 Hartmann M, Suckker C, Boehm O, Koch A, Loer S, Zacharowski K: Effects of cardiac surgery on hemostasis. Transfus Med Rev 2006;20:230-241.

3 Scott BH, Seifert FC, Grimson R: Blood transfusion is associated with increased resource utilisation, morbidity and mortality in cardiac surgery. Ann Card Anaesth 2008;11:15-19.

4 Shehata N, Wilson K, Mazer CD, Tomlinson G, Streiner D, Hebert P, Naglie G: Factors affecting perioperative transfusion decisions in patients with coronary artery disease undergoing coronary artery bypass surgery. Anesthesiology 2006;105:19-27.

5 Favaloro EJ: Clinical utility of the PFA-100. Semin Thromb Hemost 2008;34:709-733.

6 Ostrowsky J, Foes J, Warchol M, Tsarovsky G, Blay J: Plateletworks platelet function test compared to the thromboelastography for prediction of postoperative outcomes. J Extra Corpor Technol 2004;36:149-152.

7 Raman S, Silverman NA: Clinical utility of the platelet functional analyzer (PFA-100) in cardiothoracic procedures involving extracorporeal circulation. Thorac Cardiovasc Surg 2001;122:190-191.
8 Rahne-Meyer N, Winterhalter M, Boden A, Froemke C, Piepenbrock S, Calatzis A: Platelet concentrates transfusion in cardiac surgery and platelet function assessment by multiple electrode aggregometry. Acta Anaesthesiol Scand 2009;53:168-175.

9 Sucer C, Litmathe J, Feindt P, Zotz R: Platelet function analyzer $\left(\right.$ PFA- $\left.100^{\circledR}\right)$ as a useful tool for prediction of transfusion requirements during aortic valve replacement. Thorac Cardiovasc Surg 2011;59:233-236.

10 Forestier F, Coiffic A, Mouton C, Ekovevi D, Chêne G, Janvier G: Platelet function point-of-care test in postbypass cardiac surgery: are they relevant? Br J Anaesth 2002;89:715-721.

11 Fattorutto M, Pradier O, Schmartz D, Ickx B, Barvais L: Does the platelet function analyser $\left(\mathrm{PFA}-100^{\circledR}\right)$ predict blood loss after cardiopulmonary bypass? $\mathrm{Br} \mathrm{J}$ Anaesth 2003;90:692-693.

12 Poston R, Gu J, Manchio J, Lee A, Brown J, Gammie J, White C, Griffith BP: Platelet function tests predict bleeding and thrombotic events after off-pump CРB. Eur J Cardiothorac Surg 2005;27:584-591.

13 Tanaka KA, Szlam F, Kelly AB, Vega JD, Levy JH: Clopidogrel (Plavix) and cardiac surgical patients: implications for platelet function monitoring and postoperative bleeding. Platelets 2004;15:325-332.
14 Vilahur G, Choi BG, Zafar MU, Viles-Gonzales JF, Vorchheimer DA, Fuster V, Badimon JJ: Normalization of platelet reactivity in clopidogrel-treated subjects. J Thromb Haemost 2007;5:82-90.

15 Kozek-Langenecker SA, Afshari A, Albaladejo P, Santullano CA, De Robertis E, Filipescu DC, Fries D, Görlinger K, Haas T, Imberger G, Jacob M, Lancé M, Llau J, Mallett S, Meier J, Rahe-Meyer N, Samama CM, Smith A, Solomon C, Van der Linden P, Wikkelsø AJ, Wouters P, Wyffels P: Management of severe perioperative bleeding: guidelines from the European Society of Anaesthesiology. Eur J Anaesthesiol 2013;30:270-382.

16 Murphy GJ, Angelini GD: Indications for blood transfusion in cardiac surgery. Ann Thorac Surg 2006;82: 2323-2334.

17 Ranucci M, Aronson S, Dietrich W, Dyke CM, Hofmann A, Karkouti K, Levi M, Murphy GJ, Sellke FW, ShoreLesserson L, von Heymann C: Patient blood management during cardiac surgery: do we have enough evidence for clinical practice? J Thorac Cardiovasc Surg 2011;142:1-32.

18 Favaloro EJ: Utility of the PFA- $100^{\circledR}$ for assessing bleeding disorders and monitoring therapy: a review of analytical variables, benefits and limitations. Hemophilia 2001;7:170-179. 
19 Paniccia R, Priora R, Liotta AA, Abbate R: Platelet function tests: a comparative review. Vasc Health Risk Manag 2015;11:133-148.

20 Hayward CPM, Harrison P, Cattaneo M, Ortel TL, Rao AK: Platelet function analyzer (PFA)- $100^{\circledR}$ closure time in the evaluation of platelet disorders and platelet function. J Thromb Haemost 2006;4:312-319.

21 Pappalardo F, Della Valle P, Maj G, Franco A, Lattuada A, Landoni GA, Zangrillo A, D Angelo A: Perioperative evaluation of primary hemostasis in patients undergoing mitral valve repair. HSR Proc Intesive Care Cardiovasc Anesth 2010;2:119-127.

22 Yende S, Wunderink RG: Effect of clopidogrel on bleeding after coronary artery bypass surgery. Crit Care Med 2001;29:2271-2275.
23 Price MJ, Walder JS, Baker BA, Heiselman DE, Jakubowski JA, Logan DK, Winters KJ, Li W, Angiolillo DJ: Recovery of platelet function after discontinuation of prasugrel or clopidogrel maintenance dosing in aspirin-treated patients with stabile coronary disease: the recovery trial. J Am Coll Cardiol 2012;59: 2338-2343.

24 Golanski J, Pluta J, Baraniak J, Watala C: Limited usefulness of the PFA-100 for monitoring of ADP receptor antagonists - in vitro experience. Clin Chem Lab Med 2004;42:25-29.

25 Dyszkiewicz-Korpanty A, Olteanu H, Frenkel EP, Sarode R: Clopidogrel anti-platelet effect: an evaluation by optical aggregometry, impedance aggregometry, and the platelet function analyzer (PFA-100). Platelets 2007;18:491-496.
26 Pidcock M, Harrison P: Can the PFA-100 be modified to detect P2Y12 inhibition? J Thromb Haemost 2006;4: 1424-1426.

27 Tourneau T, Susen S, Caron C, Millaire A, Maréchaux S, Polge AS, Vincentelli A, Mouquet F, Ennezat PV, Lamblin N, de Croote P, Van Belle E, Deklunder C, Goudemand J, Bauters C, Jude B: Functional impairment of von Willebrand factor in hypertrophic cardiomyopathy. Circulation 2008;118:1550-1557.

28 Poston RS: Bleeding after OPCAB compared with onpump CABG. J Cardiothorac Vasc Anesth 2005; 19: 701-702. 